TITLE :

\title{
The application of geometric-morphometric shape analysis to Middle Paleolithic bone retouchers from the Altai Mountains, Russia
}

\author{
Ksenia Kolobova a, ${ }^{*}$, William Rendu b,c, Alena Shalagina a, Pavel Chistyakov a, Vasilii Kovalev a, Malvina \\ Baumann b, Anastasia Koliasnikova a, Andrei Krivoshapkin a
}

a Institute of Archaeology and Ethnography, Russian Academy of Sciences, Siberian Branch, Ak. Lavrentieva 17, Novosibirsk, 630090, Russia

b PACEA, UMR 5199, CNRS, Université de Bordeaux, Minist'ere de La Culture et de La Communication (MCC), F-33400, Pessac, France c New York University, Department of Anthropology CSHO, New York, NY, 10003, USA

\begin{abstract}
::
Here, we apply geometric-morphometric shape analysis to Middle Paleolithic bone retouchers from Chagyrskaya Cave in the Altai Mountains of southern Siberia. The cave contains evidence of the easternmost manifestation of the Micoquian industry, associated with Neanderthals at end of MIS4 and the beginning of MIS3. Taphonomic and scar pattern analyses were performed first on random samples exhibiting appropriate characteristics. Several retouchers produced on intentionally modified blanks were identified in our sample, suggesting that some of the Chagyrskaya Cave bone retouchers can be described as formal tools. All retouchers from Chagyrskaya Cave exhibit a similar general morphology. The most variable group is comprised of complete retouchers without blank modifications. Retouchers exhibiting minor damage affect the general pattern of variability and it is not possible to identify them only by means of geometric-morphometric shape analysis. Complete retouchers with blank modifications fall within the range of variability of complete retouchers without blank modification, suggesting intentional shaping of blanks to conform to a standard template. The range of variability of the bone retouchers does not differ significantly from that of the most highly modified lithic artifacts at Chagyrskaya - plano-convex bifaces - which may indicate intentional shape control for such artifacts. Geometric-morphometric analysis indicates that the anatomical origin of bone blanks does not significantly influence the retouchers' shape, which may point to strict blank selection and, at the same time, intentional modification. Our results raise questions regarding the integration of retouchers into a complex, multidimensional "chaine-op'eratoire" as well as the nature of Neanderthal cognitive abilities. Geometric-morphometric shape analysis represents a major step forward in the study of prehistoric retouchers.
\end{abstract}

Key words: Geometric-morphometric shape analysis Bone retouchers 3D modeling Altai mountains Siberia Russia Middle paleolithic Taphonomy Scar pattern analysis

\section{Introduction}

The Paleolithic of the Altai Mountains in southern Siberia is now widely known, not only because of the recent paleogenetic studies (Slon et al., 2018), but also due to the discovery of the earliest known ornamental and bone tool complex in Eurasia, dating to the transition from the terminal Middle to Initial Upper Paleolithic (Krivoshapkin et al., 2018; Douka et al., 2019). Middle Paleolithic bone tools, on the other hand, have not been documented until recently (Kolobova et al., 2016; Baumann et al., 2018; Kozlikin et al., 2019). Two waves of Neanderthal in-migration to the Altai region have been recently defined on the basis of genetic and archaeological evidence. The origin of the Chagyrskaya Cave Neanderthals has been traced back to Central-Eastern Europe and the Caucasus region. A second Neanderthal migration took place around 70-60 kyr. B.P., bringing to the Altai a specific lithic assemblage similar to the European Micoquian/Keilmessergruppen characterized by the presence of radial cores and bifacial reduction sequences. This assemblage is predominated by simple and convergent side-scrapers and retouched points (Kolobova et al., 2020a, b). Bifacial plano-convex scrapers and points including Keilmesser type are numerous (144 items). These lithic artifacts occur in association with numerous bone tools (780 items), most of which are classified as retouchers ( 680 items, 87,2\%) (Baumann et al., 2020). The identification of these bone tool complexes raises numerous questions related to the cognitive abilities of Central Asian Neanderthals and Denisovans as well as their subsistence strategies, which have not yet been investigated. In this study, we focus on bone artifact assemblage from Chagyrskaya Cave, which has yielded the largest known osseous complex in the region (Kozlikin et al., 2019). Recent advances in archaeological, paleoanthropological and paleontological researches have demonstrated the great scientific value and efficiency of geometricmorphometric analyses based on high-quality 3D models (Otarola-Castillo et al., 2017; Chen at al., 2019; Herzlinger et al., 2017; Herzlinger and Grosman, 2018; Shalagina et al., 2020). Because bone retouchers are at the interface of two crucial activities for the subsistence of the groups: the butchery and the lithic tool production, the application of this analytical approach should provide new insights for our understanding of past human behaviors. However, due to the high degree of morphological variability among bone retouchers resulting from a combination of factors (bone anatomy, breakage patterns, taphonomy, etc.), geometric-morphometric approaches were not applied to these specific components of the material culture. In addition, sample size constraints (a minimum of 30 specimens, according 
to limitation of PCA) have strictly limited the technique's effective application. Here, we test the efficacy of geometric-morphometric analyses for quantitatively characterizing the retoucher shape. This study is a first step in the application of this method to the entire Altai Middle Paleolithic record.

\section{Chagyrskaya Cave}

Chagyrskaya Cave (51。26'34.6" N; 83o09'18.0" E) is situated on the left bank of the Charysh River in the Tigirek Range of the Altai Mountains of southern Russia. The 2007-2019 excavation campaign yielded significant lithic (117,421 specimens) and bone tool (780 items) assemblages as well as faunal and Neanderthal remains. The stratigraphy is composed of several archaeological layers (Layers 5-7) attributed to the final Middle Paleolithic. Layer 6 yielded the material used for this specific retoucher analysis. A series of absolute dates attribute the Neanderthal occupation of the cave to a relatively short period during final MIS4 and the beginning of MIS3.

Paleoenvironmental data suggest that a steppe or semi-desert steppe environment prevailed under dry continental climatic conditions in the Charysh Valley at this time (Derevianko et al., 2018; Kolobova et al., 2020a,b). Abundant evidence of Neanderthal activities was uncovered in Layers 5-6c2. Layer 6c2, the lowermost in the Upper Pleistocene sequence, is preserved essentially in situ. The faunal assemblages from Layers $6 a-6 c 2$ include numerous bison remains (up to $47.2 \%$ ) resulting from Neanderthal hunting activities that focused mainly on young individuals and females. The human impact on the Layer $6 \mathrm{c} 2$ assemblage is very high (31\% of bones bear cut-marks, traces of scraping, and notches), while carnivore impact on the material is limited (8\%) (for a synthesis of the paleontological and zooarchaeological data, see Derevianko et al., 2018 and Kolobova et al., 2020b). The systematic search for anthropogenic modification of faunal remains from Chagyrskaya Cave led to the identification of a new Middle Paleolithic bone tool assemblage composed of 680 retouchers. These artifacts are associated with diverse intermediate tools, retouched tools and implements with rounded tips, the functions of which remain to be determined (Kolobova et al., 2017; Kolobova et al., 2018; Baumann et al., 2020, this volume). Chagyrskaya lithic assemblages have been associated with the Sibiryachikha Altai Middle Paleolithic variant, the easternmost manifestation of the Micoquian techno-complex (Kolobova et al., 2020a,b). Assemblages from Chagyrskaya Cave (layers 6a-6c2, 2008 excavation campaign) are characterized by flake production from radial and orthogonal cores; most flakes have trapezoidal or triangular shapes with relatively large flat or partly faceted striking platforms. The numerous toolkits (up to $30 \%$ of the assemblage, not including chips and debris) are dominated by simple and convergent scrapers of various shapes (70\% of toolkits) and retouched points (15\%). Bifacial flakes comprise up to $7 \%$ of the Chagyrskaya Cave lithic assemblage; a small component, but culturally significant in the Altai region. Here, Neanderthals undertook the selection of high-quality raw material to produce highly modified tools including convergent scrapers and bifacial implements (Derevianko et al., 2015; Kolobova et al., 2019a). Retouchers define the interface of two technical systems; those directed toward animal exploitation and lithic production (Costamagno et al., 2018); that comprise a formidable proxy for tackling the question of past hominin cognitive capacities through the analysis of a complex, multi-dimensional "chaine-op'eratoire." Layer $6 \mathrm{c} 2$ lithic assemblage demonstrate the frequent use of soft hammers by Neanderthals to produce unifacial and bifacial tools. The morphological characteristics of the proximal parts of flakes and core preparation spalls include numerous pronounced lips combined with diffused or absent bulbs in approximately $30 \%$ of the specimens examined. The pronounced bulbs and absent lips observed on the remaining flakes attest of the use of hard hammer percussion. Within the flake assemblage, only bifacial thinning flakes exhibit $100 \%$ of soft hammer reduction characteristics (Kolobova et al., 2019a). All these facts support a direct correlation between the numerous bone retouchers and the bifacial tools in Chagyrskaya Cave lithic assemblages. Prior to conduct our analysis, we have tested the efficiency of bone retouchers for the specific production of Chagyrskaya bifacial tools. According to our experimental model, the following technological sequences is observed: shaping of the flat surface, shaping of the convex surface and edge shaping. Our experiments attest of the greater efficiency of bone retouchers in comparison with hard and soft hammers for the final stages of the biface production. Moreover it demonstrates the advantages of bone retouchers in lithic tool retouching (Shalagina et al., 2020; for similar results see: Kolfschoten et al., 2015). The significant number of bone retouchers in the assemblage of Chagyrskaya Cave associated with the large number of unifacial tools strongly suggests that the first were also used for retouching the second.

\section{Materials and methods of analysis}

Bone retouchers were sampled from a large assemblage $(n=680)$ derived from Chagyrskaya Cave cultural sub-layers $6 a, 6 b, 6 c 1$ and $6 c 2$. First of all, we excluded from the analysis specimens with major breakage in their functional areas (489 specimens, $72 \%$ leaving 191 complete or almost complete retouchers, from which 40 specimens were randomly sampled from each layer for geometric-morphometric analyses. The entire sample was submitted to a thorough taphonomic analysis. Specimens were identified to the most precise taxonomic level possible and, when it was not possible to assign a specific attribution, ungulate size classes were used (Brain, 1981). Anatomical identification followed the "element, portion, segment" system of Gifford and Crader (1977). Bone surfaces of all specimens were first observed under low-oblique lighting using a 40X loupe for basic taphonomic and zooarchaeological observations. Evidence of weathering, root etching, anthropogenic and carnivore modification was systematically sought (Olsen and Shipman, 1988; Blumenschine et al., 1996; Behrensmeyer, 1978; D'Errico and Villa, 1997; Pickering and Egeland, 2006). Oxide coloration of bone cortical surfaces was also recorded and the proportion of preserved cortical surface was estimated per quartile (Rendu, 2010; Rendu et al., 2019). When uncertain modification was detected, specimens were more thoroughly examined with a 20-80X light microscope. Overall, alteration was very rare; $90 \%$ of the bones exhibit complete or nearly complete preservation of their cortical surfaces. The principal taphonomic modifications result from light weathering or root etching. The assemblage of retouchers includes the following:

1. Complete retouchers without blank modifications (Figs. 1 and 14 specimens);

2. Complete retouchers with intentional blank modifications (Figs. 2 and 10 specimens); 
The Chagyrskaya Cave bone tool assemblage includes a large number of complete or nearly complete retouchers (28\%), $30 \%$ of the tools have post-depositional damages and $41 \%$ of the retouchers exhibiting marginal damages with dry fractures. The average length of complete retouchers $-92.9 \mathrm{~mm}$, width $-37.2 \mathrm{~mm}$, thickness $-7.6 \mathrm{~mm}$, weight $-39.5 \mathrm{~g}$. Our analysis focused on evaluating how this minor damages influenced retoucher shape and geometric-morphometric results. Complete retouchers without any intentional blank modifications reflect the variability of blanks and selection criteria. Complete retouchers exhibiting intentional edge modifications marked by spall negatives were analyzed to evaluate the selection of specific blank shapes by Paleolithic artisans. Our landmark-based geometricmorphometric shape analysis generated a quantitative description of variability within and between groups of specimens. This approach is based on the calculation of shape by measurement of the distances among landmarks and semi-landmarks located on the artifact, which were later processed in Cartesian space (Herzlinger et al., 2017). We have employed Artifact GeoMorph Toolbox 3-D (AGMT3-D) to analyze retoucher shapes and followed the classical methodological approach of Herzlinger and Grosman (2018). This analytical method has become widespread among archaeologists as an effective tool for evaluating the shape of Paleolithic artifacts (lovita, 2010; lovita, 2011; lovita and McPherron, 2011; Archer et al., 2015; Morales et al., 2015; Herzlinger et al., 2017 etc.; lovita et al., 2017). Generalized Procrustes Analysis (GPA) was used as a superimposition procedure, removing non-shape related variability, thus differences in landmark coordinates can be explained only by shape differences among retouchers. Thus, artifact size was not taken into account. The AGMT3-D package allows minimization of scaling by GPA, including minimizing the data dimension at each point by Least Squares criteria. Principal component analysis was employed for data dimensionality reduction and to provide a number of new axes (components) (Lycett at al., 2006; Dryden and Mardia, 2016). The analysis has included three steps: 3D scanning and modelling, positioning and measuring of landmarks and statistical processing of data. Digital 3-D models of retouchers were created using a RangeVision PRO 5M structured-light scanner. After scanning, models were processed using RangeVisionScanCenter and RangeVisionScanMerge software (Kolobova et al., 2019b). All models were then oriented in one perspective with the active retouching area in the northern or uppermost position. Positioning and measurement of landmarks were processed with AGMT3-D software. The landmarks were established within a dense grid of $30 \times 30$, resulting in 1800 landmarks recorded per artifact. According to our sample composition, we have defined three attributes corresponding to complete retouchers without blank modifications, complete retouchers with spall negatives and retouchers exhibiting only minor damage. In order to estimate the influence of the anatomical origin of bone blanks, we have defined six additional attributes according to the anatomical composition of the sample: femur, tibia, humerus, radius, vertebra and indeterminate long bone. We have performed statistical investigations with the relevant module in AGMT3-D and PAST-3 software. The PAST program was used for one-way parametric Multivariate Analysis of variance test (MANOVA) and a non-parametric PERMANOVA test was applied to the PCA scores analyses. The univariate non-parametric Wilcoxon Rank Sum Test was used to evaluate differences between samples (Hammer et al., 2001; Herzlinger and Grosman, 2018). In order to describe retouchers exhibiting intentional spall negatives, we have performed a scar pattern/working steps analysis used to reconstruct tool-manufacturing sequences. Scar pattern analysis was based on the reconstruction of manufacturing and rejuvenation stages of lithic artifacts as well as on the chronological order of each stage in the manufacturing process (Pastoors, 2000; Kot, 2014; Shalagina et al., 2015; Shalagina et al., 2019a,b).

\section{Analytical results \\ 4.1. Zooarchaeological characterization of the retoucher}

Our sample is constituted of remains attributed to bison (NISP $=12)$, horse (NISP $=5$ ) and non-identified large ungulates (NISP $=23$ ) reflecting the other proportion already identified in the faunal spectrum. At the exception of one fragment of a transversal process of a bison vertebrae, all the blanks are made from long bones elements (Humerus: 5; Radius: 1 ; Femur = 3; Tibia $=15$; unidentified long bone = 15). The preservation of the cortical surface is good (4 pieces have more than $50 \%$ of their cortical surface altered) and only the first stages of weathering are recorded on the retoucher sample. The only potential carnivore marks are pits on the bison vertebrae and a fragment of a humerus shaft, but because of some local exfoliation on their surface, it is not possible to exclude other possibilities. Fifty percent of the blanks exhibit evidence of scraping prior to their use as retouchers and $30 \%$ display notches linked to breakage of the bone for extracting marrow and grease.

\subsection{Scar pattern analysis results}

We have analyzed retouchers with negative scars mostly on cortical bone surfaces that could not have resulted from butchery or marrow consumption processes (Grunwald, 2016; Morin and Soulier, 2017). Recent experimental studies of marrow consumption at Chagyrskaya Cave reveal that during the flaking process it is virtually impossible to generate cortical negatives, in contrast with scars on the inner, medullary surfaces of bones (Seletsky et al., 2019). The scar pattern analysis defines several types of spall negatives on bone surfaces, including those related to intentional blank modifications (Figs. 2, 1-4). The first cluster of negatives modified the initial bone shape (Figs. 2, 1, 2; negatives A). Some small negatives probably resulted from tool utilization (Figs. 2, 1, negatives B, D). Several negatives used to sharpen retoucher edges are also observed (Figs. 2, 1, negatives E; Fig. 2 and 2, negatives C, Figs. 2, 3, negatives B; Figs. 2, 4, negatives A, $B)$. Since negative scars are located on various parts of bone blanks in a less regular way than in the case of stone artifacts, the complete reduction sequence is impossible to reconstruct, except when utilization traces overlap the main modification negatives (Figs. 2, 1).

\subsection{Geometric-morphometric analysis results}

The PCA plot obtained with our geometric-morphometric approach present the variability of the retoucher shape (Fig. 4). The two first principal components account for $40.32 \%$ of the variability, which is a satisfactory outcome for geometric-morphometric approaches applied to paleoenvironmental reconstructions (Kocovsky et al., 2009; Shaukat et al., 2016). The first three principal components account for more than $49.9 \%$ of the variability. These results demonstrate that all the retouchers analyzed have a relatively similar morphology. The 
variability of complete retouchers without blank modifications (193.27) is similar to the variability of retouchers bearing minor damage (193.2). To the contrary, retouchers bearing intentional spall negatives form a less variable group (166.15). All complete retouchers exhibiting intentional spall negatives are triangular in shape. The PERMANOVA multivariable test based on all PCA scores demonstrates no significant differences among the three retoucher groups (F: 0.6971; $p: 0.8131$ ). When all groups include several specimens, the sample composition allows us to use a parametric multivariable test. MANOVA, based on the three first PCA scores (F: 0.7477; $p$ : 0.6133), confirmed the PERMANOVA results. We have performed paired tests to estimate the variability of the retoucher groups (Wilcoxon Rank Sum Test on within-group interpoint distances, on interpoint distances between-group means and on group centroid sizes). All the tests indicate an absence of difference between modified and unmodified retouchers on the one hand, and between unmodified retouchers and those with minor damages on the other. In order to understand the impact of initial shape of bone fragment on retoucher morphology, we have carried out a second geometric-morphometric analysis on the same sample. Among the 40 retoucher blanks analyzed, belonging to bisons and horses, 3 femora, 15 tibiae, 5 humeri, 1 radius, and 1 vertebra were identified, while 15 were assigned to the indeterminate long bone category. PCA plots generated from the geometric-morphometric analysis demonstrate the relative distribution of retouchers depending upon skeletal element attribution (Fig. 5). Because we analyzed the same sample, we observed the same variability coverage, thus we conclude that the nature of the blanks does not significantly influence the general variability of retouchers. At the same time, retouchers made from the same long bones demonstrate significant morphological differences (e. g., tibia or femur, Fig. 5). In the case of the small sample size groups (some groups are composed by only one specimen, such as a vertebra or radius), we were not able to use a parametric multivariable test. The PERMANOVA multivariable test based on all PCA scores demonstrates the similarity of all retouchers made on different blanks (F: 0.7782; $p: 0.8732$ ). If we exclude the two groups containing only one element (vertebra and radius), the MANOVA test based on the three first PCA scores (F: $0.5851 ; p: 0.8055)$ supports these results. Pair tests for estimating the variability of the retoucher groups (Wilcoxon Rank Sum Test on within-group interpoint distances, on interpoint distances between-group means and on group centroid sizes) also did not reveal any significant differences.

\section{Discussion and conclusions}

Appearing during the Lower Paleolithic, bone retouchers were frequently used during the Middle and Upper Paleolithic throughout the human-inhabited world. Eurasia has yielded the earliest evidence of bone blanks used as retouchers to fabricate lithic tools in Lower and Early Middle Paleolithic contexts: i.e., Caune de l'Arago (Moigne, 1996), La Micoque (Langlois, 2004), Quesem Cave (Blasco et al., 2013b); Boxgrove (Roberts and Parfitt, 1999), Terra Amata (Moigne et al., 2016), and the Gran Dolina (Rosell et al., 2011). In East Asia, the earliest bone retouchers are found at the Chinese Middle Paleolithic Lingjing site in Xuchang, Henan dated to 105-125 kyr BP (Doyon, Li, Hao, d'Errico, 2018). Numerous anatomical elements (e.g., upper limb bones, metapodials, skulls, mandibles, ribs) of large vertebrate taxa, mostly subjected to the butchery process, were used to produce various blanks. During the Upper Pleistocene, human societies may have assigned specific symbolic implications to the acquisition and use of unusual osseous tool blanks such as the Neanderthal skulls at La Quina, France (Verna and d'Errico, 2011), Ursus spelaeus long bones at Scladina, Belgium (Abrams et al., 2014) or, as in the case of some Aurignacian sites in southwestern France, large carnivore (Panthera spelaea) canines (Castel et al., 2003). Retouchers have generally been of interest to archaeologists only in the context as functional implements and are described as being produced on bone blanks, sometimes without evidence of carcass part selection (Armand and Delagnes, 1998). They have often been considered informal, opportunistic tools made on blanks randomly obtained during the process of marrow extraction (Chase, 1990; Vincent, 1993; Armand and Delagnes, 1998; Patou-Mathis and Schwab, 2002; Karavani'c and 'Sokec, 2003). According to such hypotheses, there should be no morphological similarity with the exception of function-based size: weight ratios. Consequently, geometric-morphometric analyses have many advantages such as facilitating morphological classification without reference to the size. Our application of geometric-morphometric analyses to retouchers was successful. The most variable groups are composed of unmodified retouchers and retouchers exhibiting only minor damages. Some damaged retouchers fall outside the $95 \%$ ellipse of the complete retoucher variability, indicating that taphonomy can have a major impact by occluding artifact original forms (Fig. 4). Thus, in order to reduce general variability, it is necessary to exclude damaged retouchers from the analytical sample. Based on geometric-morphometric data, it is nearly impossible to separate complete retouchers from those exhibiting minor damages, hence taphonomic studies should always be conducted prior any further investigation on bone retouchers. Complete retouchers bearing intentional spall negatives (Fig. 3) constituted the least variable group. All of the modified retouchers are triangular or sub-triangular in plan form, which underscores the necessity of conducting research on specific shapes obtained due to human modification. The scar pattern analysis reveals that the modified portions of retouchers (Figs. 2, 1, 2) could significantly influence the geometric-morphometric results. The complete retouchers without blank modification constitute the most variable group. It is important to note that complete retouchers exhibiting intentional spall negatives fall within the middle range of retouchers without blank modifications 95\% ellipse (Fig. 3). We assume that the blank modification was a significant technological stage in the retoucher shaping and the application of the approaches outlined in this study on a larger sample should confirm this hypothesis. Additionally, we have analyzed the influence of the anatomical origin of bone blanks. Our results (Fig. 5) do not demonstrate any significant effect of the anatomical origin of the bone retoucher blanks on their relative ordinal positions. Retouchers made from the same carcass elements often exhibit significantly variable shapes, suggesting that original bone morphology did not influence the morphological variability of the retouchers in our sample. This may indicate that while Neanderthals applied strict criteria to the selection of the retoucher blanks based on their physical properties (shape, weight, curvature, etc.), their specific anatomical origin was not taken into account. This may indicate the significant influence of intentional modification of blanks, whereby blanks of various shapes derived from different bones were intentionally modified to fall within certain parameters. In addition to define selectivity criteria of Middle Paleolithic retouchers (Mallye et al., 2012; Auguste, 2002; Costamagno et al., 2018), this could imply the existence of defined morphological patterns for retoucher blanks resulting from intentional selection and modification, which could change our understanding of Neanderthal subsistence strategies and 
cognitive abilities. There is a parallel between the predetermination of standardized shapes of lithic bifacial tools from Chagyrskaya Cave and the production of bone retouchers of a specific shape, accompanied by the absence of constraint on bone morphology. This implies that the selection and production of bone retouchers may have occurred very early in the butchery process, as Costamagno et al. (2018) proposed and, consequently, would constitutes evidence of the very strong imbrication of carcass processing and the selection of bone tools for the production of lithic artifacts. This is additional evidence of the role of bone retouchers as an interface between lithic production and hunting activities, and highlights their great potential for addressing the question of predetermination in complex, multidimensional "chaine-op'eratoire" and, ultimately, discussions of the cognitive capacities of our hominin ancestors.

\section{Declaration of competing interest None.}

\section{Acknowledgements}

The excavation of Chagyrskaya Cave was funded by the Russian Foundation for Basic Research (project 18-09-00041). We are thankful to the joint Russian-French Scientific Project of the Russian Foundation for Basic Research ( $N \circ$ 19-59-22007) - Fondation Maison des sciences de l'Homme (FMSH) for support of the bone tool and geometric-morphometric analysis of this research. Paleontological analysis was supported by the Russian Foundation for Basic Research (N॰18-09- 40070). Zooarchaeological analyses were funded by the CNRS, the Idex from Bordeaux University, and the French Ministry of Culture within the framework of the IRL Artemir. We gratefully acknowledge the anonymous reviewers and John Olsen for his valuable comments that deeply enriched the paper.

Abrams, G., Bello, S.M., Di Modica, K., Pirson, S., Bonjean, D., 2014. When Neanderthals used cave bear (Ursus spelaeus) remains: bone retouchers from unit 5 of Scladina Cave (Belgium). Quat. Int. 326-327, 274-287.

Archer, W., Gunz, P., van Niekerk, K.L., Henshilwood, C.S., McPherron, S.P., 2015. Diachronic change within the still bay at blombos cave, South Africa. PloS One 10 (7), e0132428.

Armand, D., Delagnes, A., 1998. Les retouchoirs en os d'Artenac (couche 6c): perspectives arch'eozoologiques, taphonomiques et exp'erimentales. In: Brugal, J.P., Meignen, L., PatouMathis, M. (Eds.), Economie pr'ehistorique: les comportements de subsistance au Pal'eolithique, XVIlle rencontres internationales d'Arch'eologie et d'Histoire d'Antibes. APDCA, pp. 205-214.

Auguste, P., 2002. Fiche 'eclats diaphysaires du Pal'eolithique moyen: biache-Saint-Vaast (Pas-de-Ca1ais) et Kulna (Moravie, R'epublique tch'eque). In: Patou-Mathis, M. (Ed.), Industrie de l'os pr'ehistorique: compresseurs, percuteurs, retouchoirs, vol. X. Soci'et'e pr'ehistorique française, pp. 39-57.

Baumann, M., Fedorchenko, A.Yu, Kozlikin, M.B., Plisson, H., Shunkov, M.V., 2018. The middle and upper paleolithic bone tools from the south chamber of denisova cave. Problems of archaeology. Ethno. Anthropol. Sib. Neigh. Terr. 24, 32-36 (in Russian).

Baumann, M., Plisson, H., Rendu, W., Maury, S., Kolobova, K., Krivoshapkin, A., 2020. Neandertal bone industry at Chagyrskaya cave (Altai, Russia). Quat. Int. this volume. Behrensmeyer, A.K., 1978. Taphonomic and ecologic information from bone weathering. Paleobiology 4, 150-162.

Blasco, R., Rosell, J., Cuartero, F., Fern'andez-Peris, J., Gopher, A., Barkai, R., 2013. Using bones to shape stones: MIS 9 bone retouchers at both edges of the Mediterranean Sea. PloS One $8(10)$, e 76780

Blumenschine, R.J., Marean, C.W., Capaldo, S.D., 1996. Blind tests of inter-analyst correspondence and accuracy in the identification of cut marks, percussion marks, and carnivore tooth marks on bone surfaces. J. Archaeol. Sci. 23 (4), 493-507.

Brain, C.K., 1981. The Hunter or the Hunted. An Introduction to African Cave Taphonomy. The University of Chicago Press, Chicago and London.

Castel, J.C., Chauvi ere, F.-X., Madelaine, F.-S., 2003. Sur Os et Sur Dents : les « retouchoirs » Aurignaciens de La Ferrassie (Savignac-de-Miremont, Dordogne). PALEO. Revue d'arch'eologie Pr'ehistorique 15, 29-50

Chase, P.G., 1990. Tool-making and middle paleolithic behavior. Curr. Anthropol. 31, 43-447.

Chen, F., Welker, F., Shen, C.-C., Bailey, S.E., Bergmann, I., Davis, S., Xia, H., Wang, H., Fischer, R., Freidline, S.E., Yu, T.-L., Skinner, M.M., Stelzer, S., Dong, G., Fu, Q., Dong, G., Wang, J., Zhang, D., Hublin, J.-J., 2019. A late middle Pleistocene denisovan mandible from the Tibetan plateau. Nature 569, 409-412.

Costamagno, S., Bourguignon, L., Soulier, M.-C., Meignen, L., Beauval, C., Rendu, W., Mussini, C., Mann, A., Maureille, B., 2018. Bone retouchers and site function in the Quina mousterian: the case of les pradelles (Marillac-Le-France, France). In: d'Errico, F., Backwell, L.R. (Eds.), The Origins of Bone Tool Technologies. Propylaeum Hannover, pp. 165-195.

Derevianko, A.P., Markin, S.V., Kulik, N.A., Kolobova, K.A., 2015. Lithic raw material exploitation in the Sibiryachikha facies, the middle paleolithic of Altai. Archaeol. Ethnol. Anthropol. Eurasia 43, 3-16.

Derevianko, A.P., Markin, S.V., Kolobova, K.A., Chabai, V.P., Rudaya, N.A., Viola, B., Buzhilova, A.P., Mednikova, M.B., Vasiliev, S.K., Zykin, V.S, Zykina, V.S., Zazhigin, V.S., Volvakh, A.O., Roberts, R.G., Li, B., Jacobs, Z., 2018. Multidisciplinary Studies of Chagyrskaya Cave - Middle Paleolithic Site in Altai. Institute of Archaeology and Ethnography, Siberian Branch of the Russian Academy of Sciences Press, Novosibirsk (in Russian).

Douka, K., Slon, V., Jacobs, Z., Ramsey, C.B., Shunkov, M.V., Derevianko, A.P., Mafessoni, F., Kozlikin, M.B., Li, B., Grün, R., Comeskey, D., Devi`ese, T., Brown, S., Viola, B., Kinsley, L., Buckley, M., Meyer, M., Roberts, R.G., P"a"abo, S., Kelso, J., Higham, T., 2019. Age estimates for hominin fossils and the onset of the upper palaeolithic at denisova cave. Nature 565 (7741), 640-644.

Doyon, L., Li, Z., Li, H., d'Errico, F., 2018. Discovery of circa 115,000-year-old bone retouchers at Lingjing, Henan, China. PloS One 13 (3), e0194318.

Dryden, I.L., Mardia, K.V., 2016. Statistical Shape Analysis: with Applications in R. John Wiley and Sons Ltd, Chichester. D'Errico, F., Villa, P., 1997. Holes and grooves: the contribution of microscopy and taphonomy to the problem of art origins. J. Hum. Evol. $33(1), 1-31$

Gifford, D.P., Crader, D.C., 1977. A computer coding system for archaeological faunal remains. Am. Antiq. 42 (2), 225-238. 
Grunwald, A.M., 2016. Analysis of fracture patterns from experimentally marrow-cracked frozen and thawed cattle bones. J. Archaeol. Sci. 8, 356-365.

Herzlinger, G., Grosman, L., 2018. AGMT3-D: a software for 3-D landmarks-based geometric morphometric shape analysis of archaeological artifacts. PloS One 13 (11), e0207890.

Hammer, Ø., Harper, D.A.T., Ryan, P.D., 2001. PAST: Paleontological statistics software package for education and data analysis. Palaeontologia Electronica 1 (4), 1-9.

Herzlinger, G., Goren-Inbar, N., Grosman, L., 2017. A new method for 3D geometric morphometric shape analysis: the case study of handaxe knapping skill. J. Archaeol. Sci. 14 , 163-173.

Iovita, R., 2010. Comparing stone tool resharpening trajectories with the aid of elliptical fourier analysis. New perspectives on old stones: analytical approaches to paleolithic technologies. In: Lycett, S., Chauhan, P. (Eds.), New Perspectives on Old Stones. Springer, New York, NY.

Iovita, R., 2011. Shape variation in aterian tanged tools and the origins of projectile technology: a morphometric perspective on stone tool function. PloS One 6 (12), e29029. Iovita, R., McPherron, S.P., 2011. The handaxe reloaded: a morphometric reassessment of Acheulian and Middle Paleolithic handaxes. J. Hum. Evol. 61, 61-74.

Iovita, R., Tuvi-Arad, I., Moncel, M.-H., Despri'ee, J., Voinchet, P., Bahain, J.-J., 2017. High handaxe symmetry at the beginning of the European Acheulian: the data from la Noira (France) in context. PloS One 12 (5). https://doi.org/10.1371/journal. pone.0177063.

Karavani'c, Ivor, 'Sokec, Tomislav, 2003. The Middle Paleolithic Percussion or Pressure Flaking Tools? The comparison of experimental and archaeological material from Croatia. Prilozi Instituta za arheologiju u Zagrebu 20, 5-14.

Kocovsky, P.M., Adams, J.V., Bronte, C.R., 2009. The effect of sample size on the stability of principal components analysis of truss-based fish morphometrics. Trans. Am. Fish. Soc. 138, 487-496.

Kolfschoten, T. van, Parfitt, S.A., Serangeli, J., Bello, S.M., 2015. Lower paleolithic bone tools from the 'spear horizon' at sch“oningen (Germany). J. Hum. Evol. 89 (1), $226-263$.

Kolobova, K.A., Markin, S.V., Chabai, V.P., 2016. Bone retouchers in the middle paleolithic complexes of Chagyrskaya cave. Theor. Pract. Archaeol. Res. 4 (16), $37-42$.

Kolobova, K.A., Shnaider, S.V., Krajcarz, M.T., Baumann, M., Markin, S.V., Alisher-kyzy, S., Seletskiy, M.V., Zavgorodnyaya, D.A., Aladjem, E., Fedorchenko, A.Yu, 2017. Research of the middle paleolithic complexes from Chagyrskaya cave in 2017. Prob. Archaeol. Ethno. Anthropol. Siberia Neigh. Terr. 23, 136-140 (in Russian).

Kolobova, K.A., Krajcarz, M.T., Baumann, M., Shalagina, A.V., Shnaider, S.V., Krajcarz, M., Berezina, N.Ya, Alisher-kyzy, S., Kolyasnikova, A., Seletskiy, M.V., Markin, S.V., 2018. The middle paleolithic complexes of the Chagyrskaya cave: 2018 field results. Prob. Archaeol. Ethno. Anthropol. Siberia Neigh. Terr. 24, 110-114 (in Russian).

Kolobova, K.A., Shalagina, A.V., Chabai, V.P., Markin, S.V., Krivoshapkin, A.I., 2019a. Signification des technologies bifaciales au Pal'eolithique moyen des montagnes de l'Altaï. L'Anthropologie 123 (2), 276-288.

Kolobova, K.A., Fedorchenko, A.Y., Basova, N.V., Postnov, A.V., Kovalev, V.S., Chistyakov, P.V., Molodin, V.I., 2019b. The use of 3D-modeling for reconstructing the appearance and function of non-utilitarian items (the case of anthropomorphic figurines from tourist-2). Archaeol. Ethnol. Anthropol. Eurasia 47, 66-76.

Kolobova, K., Roberts, R.G., Chabai, V.P., Jacobs, Z., Krajcarz, M.T., Shalagina, A.V., Krivoshapkin, A.I., Li, B., Uthmeier, T., Markin, S.V., Morley, M., O'Gorman, K., Rudaya, N.A., Talamo, S., Viola, B., Derevianko, A.P., 2020a. Archaeological evidence for two separate dispersals of Neanderthals into southern Siberia. Proc. Natl. Acad. Sci. Unit. States Am. 117 (6), 1-7. https://doi.org/10.1073/ pnas.1918047117.

Kolobova, K.A., Chabai, V.P., Shalagina, A.V., Krajcarz, M.T., Krajcarz, M., Rendu, W., Vasiliev, S.K., Shnaider, S.V., Markin, S.V., Krivoshapkin, A.I., 2020b. Exploitation of the natural environment by Neanderthals from Chagyrskaya cave (Altai). Quartar (in press).

Kot, M.A., 2014. The earliest middle palaeolithic bifacial leafpoints in central and southern Europe: technological approach. Quat. Int. 326-327, 381-397.

Kozlikin, M.B., Mikhienko, V.A., Frantseva, E.A., Shunkov, M.V., 2019. Bone retouchers from the denisova cave: new evidence. Theor. Pract. Archaeol. Res. 28 (4), 7-14.

Krivoshapkin, A., Shalagina, A., Baumann, M., Shnaider, S., Kolobova, K., 2018. Between Denisovans and Neanderthals: strashnaya cave in the Altai Mountains. Antiquity 92 (365), E1.

Langlois, A., 2004. Au sujet du Cheval de La Micoque (Dordogne) et des comportements humains de subsistance au Pl'eistoc'ene moyen dans le Nord-Est de l'Aquitaine. University of Bordeaux 1 (PhD thesis).

Lycett, S.J., von Cramon-Taubadel, N., Foley, R.A., 2006. A crossbeam co-ordinate caliper for the morphometric analysis of lithic nuclei: a description, test and empirical examples of application. J. Archaeol. Sci. 33 (6), 847-861.

Mallye, J.-B., Thi'ebaut, C., Mourre, V., Costamagno, S., Claud, 'E., Weisbecker, P., 2012. The mousterian bone retouchers of noisetier cave: experimentation and identification of marks. J. Archaeol. Sci. 39, 1131-1142

Moigne, A.-M., 1996. Utilisation des ossements de grands herbivores au Pal'eolithique inf'erieur. In: Peretto, C. (Ed.), Forli Atti XIII Congresso UISPP W 4- 6, p. 31.

Moigne, A.-M., Valensi, P., Auguste, P., Garcia-Solano, J., Tuffreau, A., Lamotte, A., Barroso, C., Moncel, M.-H., 2016. Bone retouchers from Lower Palaeolithic sites Terra Amata, Orgnac 3, Cagny l'Epinette and Cueva del Angel. Quat. Int. 409, 195-212.

Morales, J.I., Soto, M., Lorenzo, C., Verg`es, J.M., 2015. The evolution and stability of stone tools: the effects of different mobility scenarios in tool reduction and shape features. J. Archaeol. Sci. 3, 295-305.

Morin, E., Soulier, M.-C., 2017. New criteria for the archaeological identification of bone grease processing. Am. Antiq. 82 (1), 96-122. Olsen, S.L., Shipman, P., 1988. Surface modification on bone: trampling versus butchery. J. Archaeol. Sci. 15 (5), 535-553.

Otarola-Castillo, E., Torquato, M., Hawkins, H., James, E., Harris, J., Marean, C., McPherron, S., Thompson, J., 2017. Differentiating between cutting actions on bone using 3D geometric morphometricsand Bayesian analyses with implications to human evolution. J. Archaeol. Sci. 89, 56-67.

Pastoors, A., 2000. Standardization and individuality in the production process of bifacial tools - leaf-shaped scrapers from the middle Paleolithic open air site Sare Kaya I (Crimea). In: Weniger, G.-Ch, Orschiedt, J. (Eds.), Neanderthals and Modern Humans - Discussing the Transition. Central and Eastern Europe from 50.000-30.000, B. P. Neanderthal Museum, Mettmann, pp. 243-255

Patou-Mathis, M., Schwab, C., 2002. Fiche g'en’erale. In: Patou-Mathis, M. (Ed.), Industrie de l'os pr'ehistorique: compresseurs, percuteurs, retouchoirs, vol. X. Soci'et'e pr'ehistorique française, pp. 11-20.

Pickering, T.R., Egeland, C.P., 2006. Experimental patterns of hammerstone percussion damage on bones: implications for inferences of carcass processing by humans. J. Archaeol. Sci. $33(4), 459-469$.

Rendu, W., 2010. Hunting behavior and neanderthal adaptability in the late Pleistocene site of pech-de-l'Az'e I. J. Archaeol. Sci. 37 (8), $1798-1810$. 
Rendu, W., Renou, S., Soulier, M.-C., Rigaud, S., Roussel, M., Soressi, M., 2019. Subsistence strategy changes during the Middle to Upper Paleolithic transition reveals specific adaptations of Human Populations to their environment. Sci. Rep. 9, 15817.

Roberts, M.B., Parfitt, S.A., 1999. Boxgrove. A Middle Pleistocene hominid site at Eartham Quarry, Boxgrove, West Sussex ., 17. English Heritage, Archaeological Reports.

Rosell, J., Blasco, R., Campeny, G., Díez, J.C., Alcalde, R.A., Men’endez, L., Arsuaga, J.L., Bermúdez de Castro, J.M., Carbonell, E., 2011. Bone as a technological raw material at the gran Dolina site (sierra de Atapuerca, burgos, Spain). J. Hum. Evol. 61, 125-131.

Shalagina, A.V., Krivoshapkin, A.I., Kolobova, K.A., 2015. Truncated-faceted pieces in the paleolithic of northern Asia. Archaeol. Ethnol. Anthropol. Eurasia 43 (4), 33-45.

Shalagina, A.V., Kolobova, K.A., Krivoshapkin, A.I., 2019a. Scar pattern analysis as a method for the reconstruction of lithic artifacts production sequence. Stratum Plus 1, 145-154.

Seletsky, M.V., Koliasnikova, A.S., Kharevich, V.M., Kolobova, K.A., 2019. Experimental Modelling of Bone Splitting Based on the Evidence of the Sibiryachikha Variant of the Altai Middle Paleolithic. Prob. Archaeol. Ethno.Anthropol. Siberia Neigh. Terr 25, 238-244. https://doi.org/10.17746/2658-6193.2019.25.238-244.

Shalagina, A., Kharevich, V., Krivoshapkin, A.I., Kolobova, K.A., 2019b. Experimental modelling of bifacial clipping in the siberiachikha variant of the middle paleolithic in Altai. Theor. Pract. Archaeol. Res. 28 (4), 97-108.

Shalagina, A.V., Kolobova, K.A., Chistyakov, P.V., Krivoshapkin, A.I., 2020. Application of 3D geometric-morphometric analysis to the study of Stone Age lithic artifacts. Stratum Plus 1 (in press).

Shaukat, S.S., Rao, T.A., Khan, M.A., 2016. Impact of sample size on principal component analysis ordination of an environmental data set: effects on eigenstructure. Ekol'ogia 35, 173190.

Slon, V., Mafessoni, F., Vernot, B., de Filippo, C., Grote, S., Viola, B., Hajdinjak, M., Peyr'egne, S., Nagel, S., Brown, S., 2018. The genome of the offspring of a neanderthal mother and a denisovan father. Nature 561 (7721), 113-116.

Verna, C., d'Errico, F., 2011. The earliest evidence for the use of human bone as a tool. J. Hum. Evol. 60 (2), 145-157. Vincent, A., 1993. L'outillage osseux au Paleolithique moyen: une nouvelle approche. University Paris X-Nanterre. Ph.D. thesis. 